\title{
Safety and Efficacy of Early Pharmacologic Thromboprophylaxis in Traumatic Brain Injury
}

\author{
Farid Sadaka ${ }^{\mathrm{a}, \mathrm{b}}$, Yashaswi Belvadi ${ }^{\mathrm{a}}$, Maryam Sheikha, Jacklyn O’Brien ${ }^{\mathrm{a}}$, \\ Anil Srivastava ${ }^{\mathrm{a}}$, Rekha Lakshmanan ${ }^{\mathrm{a}}$
}

\begin{abstract}
Background: Patients with traumatic brain injury (TBI) are at an increased risk of developing venous thromboembolic events (VTE), including deep vein thromboses (DVT) and pulmonary emboli (PE). Pharmacologic thromboprophylaxis (PTP) is routinely delayed because of concerns of exacerbating intracranial hemorrhage (ICH) and worsening outcomes. We hypothesize that early PTP (< $72 \mathrm{~h}$ ) in TBI reduces the risk of VTE without affecting progression of ICH or worsening outcomes as compared to late PTP $(>72 \mathrm{~h})$.
\end{abstract}

Methods: We identified a total of 128 TBI patients who received PTP, and collected data including admission Glasgow coma scale (GCS), age, time of initiation of PTP, development of DVT or PE, progression of bleed on brain CT scan, death attributed to PTP and outcome (Glasgow outcome scale (GOS) at discharge from the hospital).

Results: The $<72 \mathrm{~h}$ group $(\mathrm{n}=80)$ had an average GCS of 13.6 $( \pm 1.8)$ and age of $50( \pm 21)$ yrs compared to GCS of $11( \pm 3.8)(\mathrm{P}$ $=0.0001)$ and age of $43( \pm 18)(\mathrm{P}=0.06)$ in the $>72 \mathrm{~h}$ group $(\mathrm{n}$ $=48)$. The $<72 \mathrm{~h}$ group developed $8(10 \%)$ DVTs compared with $13(27 \%)$ DVTs in the $>72 \mathrm{~h}$ group (odds ratio $(\mathrm{OR})=0.3 ; 95 \%$ confidence interval $(\mathrm{CI})=0.1-0.7, \mathrm{P}=0.01)$. There were no PEs, progression on brain $\mathrm{CT}$, or deaths attributed to $\mathrm{PTP}$ in either group. Good neurologic outcome (GOS 4-5) was present in 35 (44\%) patients in the $<72 \mathrm{~h}$ group compared to $11(23 \%)$ patients in the $>$ 72 h group $(\mathrm{OR}=2.6,95 \% \mathrm{CI}=1.2-5.8, \mathrm{P}=0.01)$ (This outcome was expected and explained by the higher admission GCS in the < $72 \mathrm{~h}$ group).

Conclusions: In our study, early PTP $(<72$ h) in TBI significantly

Manuscript accepted for publication December 27, 2013

${ }^{a}$ Departmenet of Critical Care Medicine/Neurocritical Care, Mercy Hospital St Louis, St Louis University, USA

${ }^{\mathrm{b}}$ Corresponding author: Farid Sadaka, $621 \mathrm{~S}$. New Ballas Rd, suite 4006B, St. Louis, MO 63141, USA. Email: farid.sadaka@mercy.net

doi: http://dx.doi.org/10.4021/jnr255w reduced the risk of VTE without affecting progression of ICH or worsening outcome as compared to late PTP $(>72 \mathrm{~h})$. However, the safety and feasibility of early PTP in TBI still needs to be studied in large prospective multicenter trials, taking into account the severity of TBI, type of TBI (focal versus diffuse axonal injury), and type and dosage of PTP.

Keywords: Coma; Traumatic brain injury; TBI; Thromboprophylaxis; DVT; PE; Deep vein thrombosis; Pulmonary embolus; Chemoprophylaxis

\section{Introduction}

Traumatic brain injury (TBI) is a major source of death and severe disability worldwide. In the USA alone, this type of injury causes 290,000 hospital admissions, 51,000 deaths and 80,000 permanently disabled survivors $[1,2]$. Without any treatment or intervention, from $20 \%$ to $54 \%$ of patients with TBI will develop venous thromboembolic events (VTE), deep vein thrombosis (DVT) and/or pulmonary embolism (PE) [3, 4]. In the National Trauma Data Bank, a registry enrolling 450,375 patients, TBI was an independent risk factor for VTE with odds ratio (OR) of 2.59 (95\% confidence interval (CI) 2.31 - 2.90) [5]. Significant complications and morbidities can result from development of VTE in TBI patients, from thrombophlebitis and post-thrombotic syndrome, to hypoxia, hemodynamic instability, cardiac arrest and death [6]. Extrapolating from neurosurgic patients' studies, VTE prophylaxis with pharmacologic agents (low molecular weight heparin (LMWH), or low dose heparin) is more efficacious than mechanical measures (for example, sequential compression devices (SDCs)) alone in preventing VTEs $[7,8]$. In TBI patients, the fear of progression of intracranial hemorrhage and resultant worsening outcome has hindered physicians from administering pharmacologic thromboprophylaxis (PTP). And when it is administered, PTP is usually delayed for the same reason. In this study, we hypothesize that early PTP $(<72 \mathrm{~h})$ in TBI reduces the risk of VTE without affecting progression of ICH or worsening outcomes as compared to late PTP $(>72 \mathrm{~h})$. 
Table 1. Characteristics and Outcomes of TBI Patients Receiving PTP

\begin{tabular}{|c|c|c|c|}
\hline & $<72$ h group & $>72 \mathrm{~h}$ group & P value \\
\hline $\mathrm{n}$ & 80 & 48 & \\
\hline Age (years), SD & $50(21)$ & $43(18)$ & 0.06 \\
\hline Glasgow coma scale (SD) & $13.6(1.8)$ & $11(3.8)$ & 0.0001 \\
\hline \multicolumn{4}{|l|}{ Outcomes } \\
\hline DVTs, n, \% & $8(10 \%)$ & $13(27 \%)$ & 0.01 \\
\hline PEs & 0 & 0 & \\
\hline $\mathrm{CT}$ progression & 0 & 0 & \\
\hline Deaths from VTEs & 0 & 0 & \\
\hline Glasgow outcome scale $(4-5, \mathrm{n}, \%)$ & $35(44 \%)$ & $11(23 \%)$ & 0.01 \\
\hline
\end{tabular}

Data are presented as means or $\mathrm{n}(\%)$. PTP, pharmacologic thromboprophylaxis.

\section{Materials and Methods}

We retrospectively identified TBI patients admitted to our Neuro-ICU over a 3 years period. Our 16 bed Neuro-ICU is staffed by Intensivists (board certified by the American Board of Internal Medicine in Internal Medicine and Critical Care Medicine and certified by the United Council of Neurologic Subspecialties in Neurocritical care) 24 hrs/day. We identified a total of 128 TBI patients who received PTP, and collected data including admission Glasgow coma scale (GCS), age, time of initiation of PTP, development of DVT or PE, progression of bleed on brain CT scan, death attributed to PTP and outcome (Glasgow outcome scale (GOS) at discharge from the hospital). Neurologic outcome was scored according to the five-category GOS [9] at hospital discharge for each patient. Good outcome was defined as GOS 4-5. At our institution, a weekly survey with bilateral lower extremity duplex sonography is performed on all trauma patients, including TBI patients, starting on first Tuesday after admission. All patients receive mechanical thromboprophylaxis with sequential compression devices starting on admission and applied to both lower extremities, unless injuries preclude its application. PTP is started once intracranial hemorrhage has been deemed stable and has not progressed on repeat CT scan of the head. PTP is prescribed with either LMWH (enoxoparin $30 \mathrm{mg}$ subcutaneously twice daily) or unfractionated heparin (5,000 units subcutaneously every 8 h). Progression of bleed was documented on CT scans performed after PTP was started and compared to CT scans from before PTP was started. Stable CT was defined as no progression of intracranial hemorrhage as determined by the attending radiologists' interpretation by comparing CT scan images from after and before PTP was started. The radiologists were blinded to the patient's PTP status. We dichoto- mized timing at a cutoff of $72 \mathrm{~h}$, which over the last 10 years has been the arbitrary choice of investigators looking at the issue of PTP timing in TBI $[10,11]$.

\section{Results}

The $<72 \mathrm{~h}$ group $(\mathrm{n}=80)$ had an average GCS of $13.6( \pm$ $1.8)$ and age of $50( \pm 21)$ years compared to GCS of $11( \pm$ 3.8) $(\mathrm{P}=0.0001)$ and age of $43( \pm 18)(\mathrm{P}=0.06)$ in the $>$ $72 \mathrm{~h}$ group $(\mathrm{n}=48)$ (Table 1$)$. The $<72 \mathrm{~h}$ group developed $8(10 \%)$ DVTs compared with $13(27 \%)$ DVTs in the $>72$ $\mathrm{h}$ group $(\mathrm{OR}=0.3 ; 95 \% \mathrm{CI}=0.1-0.7, \mathrm{P}=0.01)($ Fig. 1$)$. There were no PEs, progression on brain CT, or deaths attributed to PTP in either group. Good neurologic outcome (GOS 4-5) was present in 35 (44\%) patients in the $<72 \mathrm{~h}$ group compared to $11(23 \%)$ patients in the $>72 \mathrm{~h}$ group $(\mathrm{OR}=$ $2.6,95 \% \mathrm{CI}=1.2-5.8, \mathrm{P}=0.01)($ Table 1$)$. This neurologic outcome was explained by the higher admission GCS in the $<72 \mathrm{~h}$ group.

\section{Discussion}

In this study, we demonstrated that early PTP $(<72 \mathrm{~h})$ in TBI significantly reduced the risk of VTE without affecting progression of ICH or worsening outcome as compared to late PTP (> 72 h). A meta-analysis by the Brain Trauma Foundation in 2007 showed that there was insufficient evidence to guide the timing of PTP administration in TBI patients [12]. A recent meta-analysis was performed on randomized controlled trials or cohort studies that reported on the timing of PTP in TBI [13]. They also dichotomized the timing of PTP to early and late at $72 \mathrm{~h}$ post-injury. The rates of VTE and 


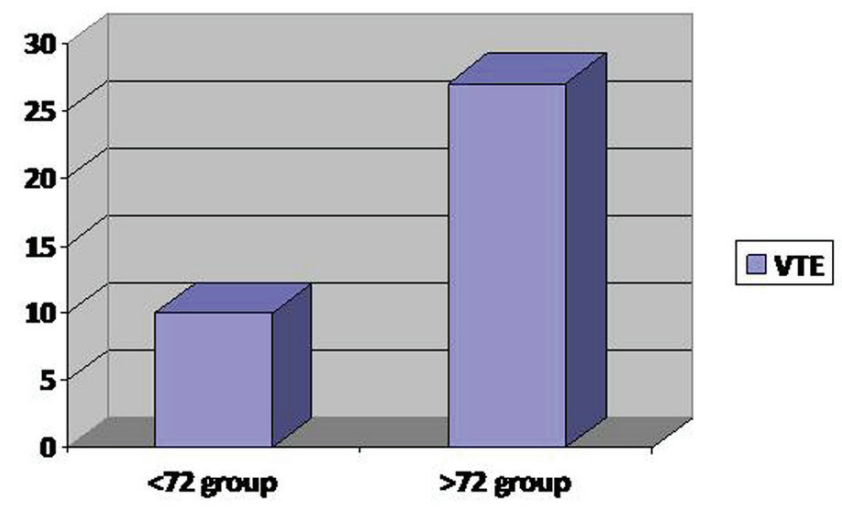

Figure 1. Difference in venous thromboembolic events (VTE) between early PTP $(<72 \mathrm{~h}$ group) and late PTP (> $72 \mathrm{~h}$ group).

intracranial hemorrhage progression were the primary endpoints. A total of five retrospective cohort studies were included within the review including a total of 1,624 patients, of which 713 received early PTP and 911 received late PTP. Within the early and late group there was a total of 43 and 106 VTE respectively, with a risk ratio of $0.52(0.37,0.73)$. Assessing safety, the relative risk of ICH progression in the early compared with the late PTP group was $0.64(0.35,1.14)$ [13]. If we add the number of patients from our study to the patients in the meta-analysis by Jamjoom and Jamjoom [13], this will add to 51 VTEs (6.4\%) in 793 total patients in the $<72 \mathrm{~h}$ group versus 119 VTEs $(12.4 \%)$ in 959 total patients in the $>72 \mathrm{~h}$ group. This would lead to similar results with a risk ratio of $0.52(0.37,0.73, \mathrm{P}=0.0002)$. Our study thus confirms findings from the meta-analysis and adds to the evidence that early PTP $(<72 \mathrm{~h})$ reduces the risk of VTE without affecting progression of ICH.

Our study has several limitations. The retrospective nature of the study and the relatively small number of patients are obvious limitations. All of the studies included in the meta-analysis are retrospective studies as well [11, 14-17]. Another common limitation among all studies, including ours, is inclusion criteria that generally consist of the presence of intracranial blood alone on CTs in TBI patients. By choosing to study TBI populations as homogenous groups is based on the wrong assumption that the risks for spontaneous progression and the times needed for stabilization of hemorrhage patterns are equivalent across all sizes and scopes of injury [17-19], which leads to the conclusion that a single VTE prevention regimen can be a "one size fits all". Our study has several strengths that would make it stand apart from the other studies. Most of the studies [11, 14, 15] did not include VTE surveillance, and patients were only imaged on clinical suspicion. Our study, however, similar to Depew's [16] and Kim's [10], had weekly VTE surveillance of the patients. In addition, looking at development of VTE's and progression of intracranial hemorrhage without looking at neurologic outcomes is not enough. Our study differs from all other studies in this respect, since we had GOS at hospital discharge as an outcome, as well as the contribution of VTEs and CT progressions to outcomes, none of which were evaluated in the other studies. Another common limitation among all studies is an inherent selection bias that cannot be controlled for in retrospective studies, namely the tendency to give early PTP to patients with stable TBI and delay PTP in cases with significant or progressive injuries.

\section{Conclusion}

In our study, early PTP $(<72 \mathrm{~h})$ in TBI significantly reduced the risk of VTE without affecting progression of ICH or worsening outcome as compared to late PTP $(>72 \mathrm{~h})$. This is in agreement with other similar studies on timing of PTP in TBI patients. Based on the current evidence, albeit retrospective, we recommend starting PTP within $72 \mathrm{~h}$ in the context of a stable follow-up CT scan. However, the safety and feasibility of early PTP in TBI still needs to be studied in large prospective multicenter trials, taking into account the severity of TBI, type of TBI (focal versus diffuse axonal injury), and type and dosage of PTP.

\section{Acknowledgement}

None.

\section{Declaration of Interest}

The authors report no declarations of interest. All authors declare that no financial or material support. All authors report that no potential conflicts of interest exist with any companies/organizations whose products or services may be discussed in this article. 


\section{References}

1. Ghajar J. Traumatic brain injury. Lancet. 2000;356(9233):923-929.

2. Rutland-Brown W, Langlois JA, Thomas KE, Xi YL. Incidence of traumatic brain injury in the United States, 2003. J Head Trauma Rehabil. 2006;21(6):544-548.

3. Kaufman HH, Satterwhite T, McConnell BJ, Costin B, Borit A, Gould L, Pruessner J, et al. Deep vein thrombosis and pulmonary embolism in head injured patients. Angiology. 1983;34(10):627-638.

4. Geerts WH, Code KI, Jay RM, Chen E, Szalai JP. A prospective study of venous thromboembolism after major trauma. N Engl J Med. 1994;331(24):1601-1606.

5. Knudson MM, Ikossi DG, Khaw L, Morabito D, Speetzen LS. Thromboembolism after trauma: an analysis of 1602 episodes from the American College of Surgeons National Trauma Data Bank. Ann Surg. 2004;240(3):490-496; discussion 496-498.

6. Kahn SR, Shbaklo H, Lamping DL, Holcroft CA, Shrier I, Miron MJ, Roussin A, et al. Determinants of healthrelated quality of life during the 2 years following deep vein thrombosis. J Thromb Haemost. 2008;6(7):11051112.

7. Agnelli G, Piovella F, Buoncristiani P, Severi P, Pini M, D'Angelo A, Beltrametti C, et al. Enoxaparin plus compression stockings compared with compression stockings alone in the prevention of venous thromboembolism after elective neurosurgery. N Engl J Med. 1998;339(2):80-85.

8. Nurmohamed MT, van Riel AM, Henkens CM, Koopman MM, Que GT, d'Azemar P, Buller HR, et al. Low molecular weight heparin and compression stockings in the prevention of venous thromboembolism in neurosurgery. Thromb Haemost. 1996;75(2):233-238.

9. Jennett B, Bond M. Assessment of outcome after severe brain damage. Lancet. 1975;1(7905):480-484.

10. Kim J, Gearhart MM, Zurick A, Zuccarello M, James L, Luchette FA. Preliminary report on the safety of hepa- rin for deep venous thrombosis prophylaxis after severe head injury. J Trauma. 2002;53(1):38-42; discussion 43.

11. Koehler DM, Shipman J, Davidson MA, Guillamondegui $\mathrm{O}$. Is early venous thromboembolism prophylaxis safe in trauma patients with intracranial hemorrhage. J Trauma. 2011;70(2):324-329.

12. Guidelines for the management of severe traumatic brain injury. J Neurotrauma. 2007;24 (Suppl 1):S1-106.

13. Jamjoom AA, Jamjoom AB. Safety and efficacy of early pharmacological thromboprophylaxis in traumatic brain injury: systematic review and meta-analysis. J Neurotrauma. 2013;30(7):503-511.

14. Salottolo K, Offner P, Levy AS, Mains CW, Slone DS, Bar-Or D. Interrupted pharmocologic thromboprophylaxis increases venous thromboembolism in traumatic brain injury. J Trauma. 2011;70(1):19-24; discussion 25-16.

15. Reiff DA, Haricharan RN, Bullington NM, Griffin RL, McGwin G, Jr., Rue LW, 3rd. Traumatic brain injury is associated with the development of deep vein thrombosis independent of pharmacological prophylaxis. J Trauma. 2009;66(5):1436-1440.

16. Depew AJ, Hu CK, Nguyen AC, Driessen N. Thromboembolic prophylaxis in blunt traumatic intracranial hemorrhage: a retrospective review. Am Surg. 2008;74(10):906-911.

17. Bee TK, Magnotti LJ, Croce MA, Maish GO, Minard G, Schroeppel TJ, Zarzaur BL, et al. Necessity of repeat head CT and ICU monitoring in patients with minimal brain injury. J Trauma. 2009;66(4):1015-1018.

18. Chang EF, Meeker M, Holland MC. Acute traumatic intraparenchymal hemorrhage: risk factors for progression in the early post-injury period. Neurosurgery. 2006;58(4):647-656; discussion 647-656.

19. Park HK, Joo WI, Chough CK, Cho CB, Lee KJ, Rha HK. The clinical efficacy of repeat brain computed tomography in patients with traumatic intracranial haemorrhage within 24 hours after blunt head injury. Br J Neurosurg. 2009;23(6):617-621. 